Please do not remove this page

RMIT

UNIVERSITY

\title{
Part-time and part-committed?: The challenges of part-time work in policing
}

Charlesworth, Sara; Whittenbury, Kerri

https://researchrepository.rmit.edu.au/esploro/outputs/9921858856801341/filesAndLinks?institution=61RMIT_INST\&index=null

Charlesworth, S., \& Whittenbury, K. (2007). Part-time and part-committed?: The challenges of part-time work in policing. Journal of Industrial Relations, 49(1), 31-47. https://doi.org/10.1177/0022185607072237

Published Version: https://doi.org/10.1177/0022185607072237

Repository homepage: https://researchrepository.rmit.edu.au

(C) Industrial Relations Society of Australia

Downloaded On 2023/04/26 12:27:00 +1000

Please do not remove this page 
'Part-time and Part-committed'?: The Challenges of Part-time Work in Policing

Sara Charlesworth

Kerri Whittenbury

Centre for Applied Social Research

RMIT University

GPO Box 2467V

Melbourne 3001

Corresponding author:

Sara Charlesworth

Phone: (03)99253354

Email: sara.charlesworth@rmit.edu.au

Citation:

Charlesworth, S and Whittenbury, K 2007, 'Part-time and part-committed?: The challenges of part-time work in policing', Journal of Industrial Relations, vol. 49, no. 1, pp. 31-47 


\begin{abstract}
In police services, both in Australia and internationally, attention has been focused on increasing the representation of women. The availability of parttime work has been identified as a key mechanism to retain women who have been recruited. To date however the take-up of part-time work remains low. It is also concentrated in administrative work and non-operational policing work. In this paper, we draw on research in Victoria Police around the experiences of, and attitudes towards, part-time work. The research suggests that there are a number of policy constraints to the take up of part-time work, particularly by police officers. There are also significant cultural barriers to both increasing and integrating part-time work, which influence attitudes to part-time work at all levels of the organisation. However, these barriers are intertwined with and reinforced by institutional structures and processes that position part-time work as 'other' and a gendered understanding of police work. In increasing access to part-time work, the challenge for police services is to address both institutional and cultural barriers to the integration of parttime and full-time work.
\end{abstract}

\title{
Introduction
}

In April 2003, Australia’s only female Police Commissioner, Christine Nixon, announced that Victoria Police would seek an exemption from Victorian antidiscrimination legislation to ensure that at least 50 percent of police recruits are women. The aim was for women to comprise a quarter of all police officers by 2007, rather than the less than 18 percent as they do currently (Epstein 2002). While this explicit commitment to recruiting women police caused some controversy and criticism (see for example de Kretser 2003; de Kretser \& Butler 2003), it is reflective of moves, both in Australia and internationally, to increase the number of women in police services. Better representation is seen as critical for a number of reasons. Apart from the broader issue of compliance with anti-discrimination and equal employment opportunity (EEO) provisions, gender balance within police organisations is generally accepted to be desirable to ensure that police services are responsive to, and representative of, the communities they serve (Eveline \& Harwood 2002) and because women bring specific skills seen as vital to police work more generally (Manders 2000). Police Royal Commissions in both Queensland and New South Wales have also identified women as a target group, whose recruitment would assist in eliminating the negative aspects of a 'cop culture’ (Fleming \& Lafferty 2003, 47).

Despite the increasing promotion of policing as a career for women, women constitute just 21 percent of the Australian police workforce (AIC 2003). While women continue to be recruited in slowly increasing numbers, there is some evidence that the rate of retention is much lower for women than for men, with 'family/domestic' reasons a major factor in resignations (Prenzler \& Hayes 2000, 28). One of the significant barriers to retaining women both in sworn and unsworn positions in police work is the limited provision and uptake of part-time work (Rose 2002). To date some emphasis has been placed on ensuring that part-time work is available to police on their return from maternity leave. This is seen as a crucial retention mechanism. However available 
evidence suggests part-time work in policing remains limited and associated with disadvantage. In Australian policing services, for example, just over four percent of sworn and unsworn staff work on a part-time basis (Victoria Police 2005). This is much lower than for the total Australian workforce where 29 percent of all employees are employed on a part-time basis (ABS 2005). ${ }^{1}$

It is not just the scarcity of part-time police positions that presents an issue. Part-time work in police services is concentrated in the lower ranks for police officers (sworn members) and in lower level public service positions (unsworn staff). Women account for the overwhelming proportion of part-time employees in general and in police services in particular, with most of the available part-time jobs in police services being held by women and located at the bottom of the police hierarchy in non-operational positions. Typically such positions have poor career prospects and enjoy ambivalent management and peer support (BAWP 2002; Leane \& Durand 2002). These factors suggest that this part-time work is marginalised and of poorer 'quality' than full-time work. The central problem is not so much the inherent work value of these jobs, but rather the poorer conditions and the disadvantages that are associated with them relative to full-time work. The limited uptake of part-time work, even where it is apparently available, may well be influenced by perceptions of its marginal status within police work. To recruit and retain women, the challenge for police services is not only to increase the quantity of part-time work available but also the 'quality' of that work. In short, this means ensuring that part-time work is an integrated rather than marginalised form of employment. (Fagan 1999, 58).

This paper seeks to better understand the nature of these challenges, drawing primarily on an internal review of part-time work within Victoria Police. The second section of this paper sets out the background to part-time employment within Victoria Police, including current policy and the structure of part-time employment in that policing service. The third section describes the main policy barriers to part-time employment identified in the internal review of part-time work. The fourth and most substantive section then examines a number of broad cultural issues identified as limiting both the quantity and quality of part-time work in Victoria Police. We argue that such cultural issues cannot be sheered off from organisational practices and institutional barriers such as the organisation and scheduling of police work, opportunities for training, the promotions process and the staffing of residual positions. We focus in this paper on the particular experiences of part-time work in police officer (sworn) employment.

\section{Part-time Work in Victoria Police}

Victoria Police is Australia's second largest policing jurisdiction after New South Wales, with almost 13,000 sworn and unsworn personnel in 2003 (AIC 2003). In international terms it is a large police services with an annual budget of $\$ 1.2$ billion and 328 police stations around the State (Victoria Police 2004b). Since 1973, women have been able to be appointed to all branches of the organisation and the numbers of sworn female personnel have slowly increased to comprise 15.5 percent of police officer employment in 2004 (Victoria Police 2004b). ${ }^{2}$ Today, just over three percent of police officers work in part-time positions, as do nine percent of Victoria Police public service employees (Victoria Police 2004b). 
In 1992, a part-time pilot program was introduced at Victoria Police, consisting of 10 positions identified as suitable for part-time work. The pilot program was deemed a success and in 1996 a formal part-time employment policy was introduced. As part of wage negotiations at the time between the Police Association and Victoria Police, it was agreed that the organisation would introduce a minimum of 100 part time policing positions (Hogan 1999). Updated in 1998, the policy applies only to sworn members. Non-sworn public service members are covered by the Victorian Public Service Enterprise Agreement (Australian Industrial Relations Commission 2004).

The current part-time employment policy has specific eligibility criteria that must be satisfied in order for an employee to work part-time. Prospective part-time workers must meet one of three criteria for eligibility: combining work and family responsibilities; undertaking a course of study; or meeting specific ongoing needs related to a medical condition or disability. Probationary constables are specifically exempted from the policy. Under the terms of the current policy, part-time work is of a limited four year timeframe and is subject to annual review. Staff are also required to prepare a business case in support of any application for part-time work, outlining how the proposed arrangements could be accommodated in their work area. In order to obtain part-time work employees can either apply to convert their existing full-time position to a part-time position or apply for an existing part-time vacancy. Survey data from the internal Part-time Employment Review outlined below indicates that 56 percent of part-time respondents had applied to convert their full-time position to parttime with 28 percent applying for an advertised part-time vacancy and a further 16 percent being able to access a part-time role for which they did not apply (Victoria Police 2004a).

Since the introduction of the formal part-time employment policy in 1996, part-time employment has grown steadily from approximately 100 employees, both sworn and unsworn (Victoria Police 2004a). In June 2003, Victoria Police had a total of 563 parttime employees, 4.4 percent of its total employees. ${ }^{3}$ Victoria Police ranks fifth of the eight Australian policing agencies in terms of its proportion of part-time employees. Tasmania had the largest proportion of part-time employees at 7.7 percent and Northern Territory Police the lowest proportion at 1.0 percent (Victoria Police 2004a). In Victoria Police, as in other Australian police services, part-time employment is concentrated amongst unsworn members with only 3.4 percent of sworn employees working on a part-time basis compared to 9 percent of unsworn employees in 2003 (Victoria Police 2004a). Part-time work is overwhelmingly taken up by women, who in 2003 comprised 87 percent of all part-time employees at Victoria Police (Victoria Police 2004a).

Insert Table 1 about here

As set out in Table 1, the latest data available indicates that part-time employment continues to grow, increasing from 361 sworn members in 2003 to 420 in 2004 . While more men are working part-time, the majority of part-time police employees (83 percent) are women. The current policy does not specifically exclude any classification apart from probationary constables. However, all part-time work in Victoria Police in 
June 2004 was located at the Sergeant classification or below. As discussed further below, the absence of part-time work in higher classifications appears to reflect the influence of cultural and institutional barriers to part-time work within Victoria Police.

Both the policy and practice of part-time work in Victoria Police has come under recent scrutiny in two studies. The first was the internal Part-time Employment Review that focused on police officer (sworn) and public service (unsworn) positions. Funded by the Victorian government under its Partners at Work scheme, ${ }^{4}$ the Review was undertaken in 2003-2004 in consultation with both the Police Association of Victoria (PAV) and the Community and Public Sector Union (CPSU). The main aim of the Parttime Employment Review was to ascertain the extent to which part-time work contributed to the flexible work practices identified as a priority under the Victoria Police strategic plan (Victoria Police 2002). Oversighted by an internal reference group with representatives of both the PAV and the CPSU, the wide ranging and comprehensive study included documentary analysis, preliminary interviews, 21 focus groups with 107 participants, 20 written submissions and two surveys; one distributed to personnel currently working part-time in Victoria Police (with 284 respondents) and one distributed to a random sample of full-time personnel who manage, supervise, work or have some contact with part-time employees in Victoria Police (with 86 respondents) (Victoria Police 2004a).

While this paper draws primarily on the findings of the Part-time Employment Review, it is also informed by interviews undertaken as part of a study on quality part-time work currently being conducted by the Centre for Applied Social Research at RMIT University in partnership with Victoria Police. ${ }^{5}$ The Policing and Quality Part-time Work project aims to identify and evaluate the current constraints on, and options for, quality part-time work in Victoria Police and to develop a framework for the implementation and evaluation of quality part-time work in policing. Oversighted by a reference group, which includes a cross section of police representatives, the researchers and representatives of the PAV and the CPSU, the project incorporates an action research methodology in which Victoria Police employees are taking an active role in identifying the need for, and the implementation of, changes in organisational processes and practices as they relate to improving both access to, and the quality of, part-time work. The first stage of the Policing and Quality Part-time Work project, undertaken in 2004 and early 2005, built on the findings of the Part-time Employment Review. That stage focused on looking at the practice of part-time work across the broader organisation and has involved more than 30 formal interviews, informal discussions, participant observation and the analysis of internal data and documentation. ${ }^{6}$

\section{Policy Barriers to Quality Part-time Work}

What do we mean when we refer to quality part-time work? One way to think about quality, as noted above, is to look at the extent to which part-time work and part-time workers are integrated or marginalised within a workplace and organisation. In very simple terms, a quality part-time job can be understood as a 'good' or 'decent' job, and in an organisation such as Victoria Police, comparable to a full-time job, apart from reduced hours, in its conditions, opportunities and benefits. Broad indicators of quality part-time work include: effective access to part-time work at all occupational and seniority levels for both men and women; the same protections as full-time work in respect to job protection, predictability of hours, working beyond contracted hours and 
discrimination; pro-rata wages and access to benefits; equal access to training and career progression; and being able move between full-time to part-time work (Charlesworth et al 2002, 87).

The Part-time Employment Review identified a number of policy obstacles both to increasing the availability of part-time employment across Victoria Police and to integrating that employment where it is negotiated. In terms of access, the main barriers identified include the exclusion of probationary constables, the eligibility criteria and the time limitations. The policy exclusion of probationary constables from part-time work relates directly to the time limits imposed on the confirmation process for constables. ${ }^{7}$ The training of recruits is conducted on a full-time basis, which contributes to a conception of 'normal' police employment as full-time.

Criteria for conversion of a full-time position to a part-time position listed above exclude those who wish to work part-time for lifestyle reasons or to phase their retirement. The requirement to provide a reason for working part-time was also seen to contribute to the perception that working full-time is the norm and that any departure from full-time work is 'abnormal'. The limited time frame of part-time work to four years also positions part-time as 'other' to the perceived/implicit full-time organisational norm. Part-time work is seen as something temporary that arises due to an employee's temporary need. This view of part-time work as temporary may has implications for the quality of part-time work as it is a barrier to part-time career progression. The implied full-time norm reflects a perception of work that is structured around the unencumbered 'ideal worker' who is available to work full-time and overtime and whose family and domestic needs are provided for by someone else (Williams 2000; Bailyn \& Fletcher 2003).

In addition to such barriers in the written part-time employment policy, the Review also found the policy implementation process presented a number of difficulties for those who wished to work part-time and for those who managed them. Such difficulties included the approval process, the management of left over or residual hours from parttime conversions and practical difficulties associated with returning to full-time work. Requirement for sign off at a number of levels up the chain of command in the approval process led to time delays for those who wanted to convert to part-time work and some frustration for their managers who felt as if they had little power to negotiate and/or decline applications. The Review identified some confusion about the fate of residual hours left over when a full-time position is converted into part-time employment. While there are opportunities to combine residual hours from more than one part-time conversion to form another part-time or full-time position, some managers were unaware of such possibilities while others reported that there were practical difficulties in doing so, particularly when the residual time fraction was small.

Many of those who were part-time at the time of the survey intended to keep working on a part-time basis. However almost one in four of the respondents to the part-time staff survey indicated that they planned to return to a full-time position in Victoria Police. Some part-time focus group participants were concerned about both their entitlement to return to full-time work and the practical difficulties of doing so, particularly when another staff member had filled the residual hours. Such concerns were also echoed by a number of managers who attended focus groups. They indicated 
that while they had mostly been able to accommodate the relatively infrequent requests to move back to full-time work, where there was low staff turnover or where staffing levels were at their maximum, some staff had had to move to different work units when they returned to full-time work.

As a result of the Part-time Employment Review, Victoria Police is currently developing a new part-time employment policy. While policy changes relating to parttime employment are an important development, policy initiatives on their own are unlikely to have a substantial impact in the area of part-time employment (Eveline \& Harwood 2002). Not surprisingly then and consistent with other research findings focusing on Victoria Police (Short 2004) and on other police jurisdictions (Dick 2004; Edwards \& Robinson 1999; Eveline \& Harwood 2003), the Part-time Employment Review identified a need for widespread cultural change across the organisation in respect to part-time work.

\section{Cultural and Institutional Barriers to Part-time Work}

Calls for cultural change within policing organisations can appear predicated on a conceptualisation of 'police culture' as static and monolithic, quite divorced from the socio political and organisational contexts of police work (Chan 1996; Prenzler 1997; Poaline 2003). However, what we may understand as 'police culture' may be a diversity of cultures (Prenzler 1997, 49), a compilation of different sub-cultures within policing organisations that include ambiguous and contradictory aspects. Indeed there is increasing recognition that a conceptualisation of police culture as uniform and monolithic is less than helpful (Poaline 2003, 204). Organisations, like any community, are made up of individuals who may have diverse attitudes and beliefs. In a large organisation such as Victoria Police, in addition to individual variation, there is locality and departmental knowledge that is specific to particular contexts. Different aspects of the organisation share their own particular culture, or sub-culture. Nor are these cultures static; they arise, are supported and change within a workplace or organisational context.

Nevertheless, there is frequently a dominant or overriding set of values accompanied by supporting attitudes, beliefs and a stock of 'common knowledge' held by members of an organisation, or indeed of an occupation. Beliefs and perceptions arising from such dominant values are transmitted within an organisation and may influence the organisation member's worldview and come to be accepted as taken-for-granted 'knowledge' (Whittenbury 2003). Organisations that are embedded within an occupation such as policing exert a cultural influence on members (Poaline 2003, 204). While there may be variation between the cultures in various parts of the organisation, and across various ranks, the distinctive historical and law enforcement environment within which policing is undertaken contributes to a construction of police work as masculine. Thus gendered conceptions of police work (Eveline \& Harwood 2002) both reflect and support the way policing is organised and staffed, with many of the small proportion of women employed in policing being concentrated in areas deemed 'suitable' or 'appropriate' while the 'real' police work of fighting crime is largely left to men (Dick \& Cassell 2004).

Cultural processes are however enmeshed with institutional or structural processes. While there may be attempts to unravel such processes for analytical purposes, in 
practice they are intertwined (Whittenbury 2003). Policing practices, such as those around part-time work, need to be understood in terms of the interaction between cultural knowledge or 'dispositions' and more structural and historical factors (Chan 1996, 115). That is, the ways in which part-time work is perceived in the policing context will draw on taken-for-granted knowledge, including understandings of what constitutes police work, and the traditional organisation of policing work around fulltime work and shifts. Such attitudes in turn are informed by and influence the task environment (Prenzler 1997, 48), the ways in which policing work is resourced and organised, and how policing knowledge and skills are valued. Institutional and organisational processes may be influenced by cultural considerations. The part-time policy and its implementation that constructs part-time work as temporary and a deviation from 'real' policing work is influenced by a belief that the women who want to work part-time are committed to their families rather than to their work, an understanding that also serves to explain, if not justify, the concentration of part-time employment at the lower levels of the police hierarchy. In a similar vein, cultural beliefs may be influenced by institutional, or structural, processes. One such belief is the view that part-time workers lack career ambition. This view is apparently supported by the fact that few part-time employees apply for promotion. However, the promotion process for part-time employees is fraught with obstacles and there is a dearth of part-time positions advertised, for which current part-time staff might apply.

The Part-time Employment Review identified several cultural issues and culture related perceptions that are relevant in this context: the commitment of part-time employees; interpretations of the concept of 'choice'; development and promotion; generational and gender diversity; and hierarchical organisation. As highlighted below resourcing and institutional practices and processes clearly inform and interact with such perceptions.

Perceptions about part-time officers' commitment to the organisation have been aptly described in the context of UK policing services as a 'part-time, part able, part committed' discourse (Jenkins 2000, 23). For some within Victoria Police, work commitment is measured by time spent at work, or 'face time'. This perception can have negative repercussions for part-time workers who may be perceived as less committed than full-time workers.

See I think one of the problems for women, women who, probably even more so for men, who go part time is that there's this attitude out there that you're not really committed to the job if you want to work part time... I've taken two lunch hours... I've taken lunch twice since I've come back to work... I focus a lot on my work and I think most part-timers compact a lot more into a short period of time and are very committed to the organisation and I think there's often unfair criticism levelled at ... some women or some men who are out in the operational areas that there's a lack of commitment because you don't want to work full-time. (Female, senior position, works part-time. Source: 'Policing and Quality Part-time Work: Constraints and Options' project).

The perception that part-time workers are less committed than those working full-time is typical of workplaces more generally (see Junor 1998; Charlesworth 1999). A construction of police work as putting up with danger, unsociable shifts and long working hours (Dick \& Cassell 2004, 66) works to define commitment as being able to 
undertake such work on a full-time basis. By extension those who do not or are perceived not to 'measure up' are viewed as somehow uncommitted. The Part-time Employment Review found that measuring commitment in terms of the amount of time spent at work was quite common. Well over a third of survey respondents who manage, supervise, work with or have contact with part-time employees believed they were less committed than full-time employees. There also appears to be an association made between less masculine areas of police work and their suitability for part-time work. The positions within policing generally considered suitable for women; for instance sexual assault and child abuse units, community policing and school liaison, are also seen as more suitable for part-time work. However, those who take on the more dominant masculine occupational identity of police work are unlikely to want to work with or support those who work part-time. This is reflected quite vividly in perceptions identified in the Review that particular roles, work areas and levels of work, including specialist areas of policing such as the Special Operations Group and areas where work is organised in teams, or squads, such as criminal investigation, are simply unsuitable for part-time work.

The main reason part-time work is taken up in Victoria Police is to support work/family balance, a factor which also helps contribute to a construction of part-time work as 'other'. Issues of work-life balance have tended to be viewed as women's issues. Parttime employment and flexible work options generally, are perceived by many in Victoria Police as being for 'just' women with children. The Review suggests that this perception has two main consequences. Firstly, it feminises part-time work and secondly, it works to inhibit men who want to work part-time, at least for work family reasons. Interestingly, working less than full-time for reasons other than family responsibilities may be seen as somewhat more acceptable. In a complaint of sex discrimination pursued under the Victorian Equal Opportunity Act 1995 by a detective whose application to work on a part-time basis for family reasons had been refused, evidence was produced suggesting that working part-time to study or taking time off to train for police sporting events was not seen to demonstrate the same 'lack of commitment' that working part-time for work/family reasons did (Hogan 1999; Robertson 2002).

Perceptions about the concept of 'choice' were raised by managers in focus groups conducted as part of the Part-time Employment Review. When discussing the need for flexible work arrangements to accommodate women's family responsibilities, some of the respondents suggested that it was a woman's 'choice' to have children. Some managers suggested that prior to women 'choosing' to have children they should consider whether they will be able to continue to meet the requirements of the job. This perception highlights both the full-time mode in which work is predominantly organised and the influence of the male breadwinner model, given that men in Victoria Police are not expected to 'choose' between a career and having children. Preliminary investigations conducted under the Policing and Quality Part-time Project suggest that of the (very) few women who hold senior positions in the organisation, most have neither married nor raised children. This suggests that for women, family responsibilities have hampered progression to senior management positions and is indicative of a gendered culture that treats women with family responsibilities differently. 
Development and promotion were identified in the Part-time Employment Review as cultural barriers to the organisational acceptance of part-time work. The reduced quantum of time spent at work by part-time police officers together with the perception that they may be less committed to their work can mean part-time staff are overlooked for training and development opportunities. Simply not being in the workplace when decisions about training are being made might also affect part-time employees’ participation in training and development programs. The structure of training and development may also adversely impact on the ability of part-time staff to participate in such programs. Many programs are modelled on full-time attendance, with some having residential components. It may be difficult for part-time staff to attend training programs held on days when they are not usually at work. The survey of part-time staff conducted as part of the Review found that 44 percent of respondents had undertaken short courses but only 14 percent had undertaken any longer-term training courses.

Temporary upgrading to higher duties is a common way for Victoria Police employees to experience working at a higher level and is often a precursor for promotion. Part-time staff were significantly underrepresented in participating in upgrading with more than four-fifths of respondents to the Part-time Employment Survey indicating that they had not had the opportunity to undertake upgrading/higher duties since becoming part-time. Many current part-time staff believe their opportunities for career progression are severely limited by working on a part-time rather than full-time basis. Very few parttime workers attending focus groups run as part of the Part-time Employment Review had obtained a promotion while working part-time with a common view expressed by several that 'I have basically resigned myself to the reality that by converting to parttime, my career is over' (Victoria Police 2004a, 60).

The Quality Part-time Work project has also identified limitations to maintaining parttime employment status when applying for promotion. While not part of formal procedure, a widespread and accepted organisational practice has been that a part-time employee seeking promotion must apply for a full-time advertised position and then make application to have the new full-time position converted to part-time, unless a part-time position at the appropriate rank has been specifically advertised. Several interviewees suggested that it is not advisable to openly state their intention to apply to convert the sought after position to part-time as this is likely to work against their obtaining the position:

You have to wait for a position (to be advertised) and then you apply and that's what's interesting because there's never any part-time positions you have to convert them all the time so if you go there from a part-time status the first thing that they say is it's a full-time position.

(Question) So would you then apply for that full-time, get in there and then try and convert it?

Yep. (I) Wouldn't flag that that was what I was going to try to do and any woman that always asks me that, I say to them don't flag it because you'll never get it... Never flag it. No because there's not a strong policy there, although one would argue they're discriminating but it would be a long drawn out process [to 
complain] (Female, Senior Constable, works part-time. Source: 'Policing and Quality Part-time Work: Constraints and Options’ project).

As mentioned above, implicit and taken-for-granted norms that both reflect and reinforce the male breadwinner model of full-time employment underpin the way police work is traditionally organised. Victoria Police remains an hierarchical organisation and, while this is changing somewhat, progression to higher level positions in the organisation is predominantly based on seniority. Coupled with Victoria Police being a male dominated organisation, this means that most senior management positions are held by men of what the Review refers to as 'Veterans' or 'Baby Boomers' generations. According to the Review, people from these generations tend to have more traditional views of work and gender based on their own experiences and do not expect much workplace flexibility. This contrasts with younger workers from Generations ' $X$ ' and ' $\mathrm{Y}$ ' who, according to the Review, expect workplace flexibility and subscribe to less traditional gender roles. It is however noteworthy that preliminary interviews and observations undertaken for the Review found a number of instances of younger men who appear to subscribe to the more traditional view of gender roles as evidenced by their descriptions of their own family circumstances. This does not support the notion that 'traditional' views concerning gender roles are the province of specific generations or that such views will simply disappear with the effluxion of time.

We have focused in this paper on the cultural barriers to part-time work identified in the internal Victoria Police Part-time Employment Review. However as we have noted such cultural barriers are intertwined with organisational and institutional barriers such as the organisation and scheduling of police work, opportunities for training, the promotions process and the staffing of residual positions. As an illustration of the interaction of both cultural and institutional factors, both the Part-time Employment Review and interviews undertaken in the first stage of the under the Policing and Quality Part-time Project suggest that considerations such as 'backfilling' of residual hours, left over when a fulltime position is converted to part-time, can effect experiences of and attitudes toward part-time work. Sometimes residual hours are unfilled, which leads to further staffing pressures in already tight work units. ${ }^{8}$ In some instances, residual hours are advertised and filled as another part-time position and in other instances, managers have pooled residual hours from two or more converted positions to create another full-time job. However local work areas may lose the residual hours of full-time to part-time work conversions to other work areas in the district or division, which can work to discourage local managers from supporting part-time work. Although such reallocation, or lack thereof, of resources is an organisational responsibility, part-time staff members may be held accountable by line managers and co-workers for work units being under resourced in terms of staff.

At the same time, while structural and institutional processes are crucial underpinnings of attitudes to part-time work within Victoria Police, the interpretative and active role of police officers in structuring their understanding of the organisation (Chan 1996, 112) should not be underestimated. The Review uncovered an important perception about part-time work that illustrates the cultural construction of part-time police members as somehow less committed to taking on the real work of policing than full-time members. This perception, also raised in the first stage of the Policing and Quality Part-time Work Project, relates to set shifts and the belief that part-time workers were able to negotiate 
set shifts and avoid the less desirable/anti-social hours, thus leading to inequity between those who perform shiftwork and those who do not. In close examination of the Review data relating to shift work, it appears in fact that an overwhelming majority of the parttime staff who participated in the Review and who hold positions where shift-work occurs, participate in all shifts. The data are not clear on whether this includes rotating shifts. However, the vast majority of part-time police members work day, afternoon, night and weekend shifts where applicable. These findings are in contrast to the perceptions expressed by managers and other full-time workers. While managers may have positive experiences of supervising part-time staff in their own work area, they nevertheless tend to generalise about the 'problem' of set shifts in other work areas (see also Edwards \& Robinson 1999, 11), with the constant 'telling' of this problem providing evidence of its existence (Chan 1996, 114). This is a vivid example of the way certain beliefs and perceptions that may be culturally transmitted within an organisation become accepted as taken-for-granted 'knowledge'. Interestingly while there are many full-time roles in policing that do not require shift work, this is not typically seen as a source of inequity (Dick 2004, 309).

\section{Concluding Comments}

Part-time employment has been available, albeit in a limited form, in Victoria Police since it was first piloted in the organisation in 1992. Scant consideration was given to the quality of part-time jobs as the (reduced) quantity of working hours was viewed as the most important criteria of a part-time job. 'Job quality' is, in part, a subjective notion and in some cases has been equated with the concept of job satisfaction (see Green 2005). While subjective aspects are important, our approach to understanding job quality also includes more objective characteristics. Job quality incorporates a number of dimensions (see Chalmers et al 2005) of which job content and schedule of work hours are particularly relevant to experience in Victoria Police. When an employee converts from full-time to part-time ${ }^{9}$ the content of the job may change. Part-time police employees may be given more routine clerical tasks and not assigned to the variety of activities experienced by full-time police, because for example part-time staff are deemed to 'cause' a lack of 'continuity' in police work. Interestingly, this continuity criticism is only made in relation to part-time employment. ${ }^{10}$ Other factors, such as changes to work hours due to shift rotation, court attendance, roster changes and staff redeployment are not viewed as disrupting the continuity of 'full-time' police work in the same way.

Part-time work is concentrated in the lowest three ranks in Victoria Police. In June 2004, the nine rank levels above Sergeant had no instances of part-time employees, even though there are no policy barriers to part-time employment at these ranks. There are however important and interrelated cultural and institutional barriers to part-time work. The assumption that particular jobs in Victoria Police are not amenable to parttime work, coupled with a prevailing attitude that views part-time work as 'just' for women with children has implications for the quality of part-time work in terms of its location in the organisation and for the content of part-time jobs, as does the traditional organisation of policing work around full-time work. For part-time and full-time employment to be fully integrated, part-time employment needs to span all ranks of the organisation at more than token levels, thereby normalising part-time work in the organisation. 
The Part-time Employment Review made a substantial number of specific recommendations addressing both the policy and cultural issues highlighted in the review findings. These recommendations are yet to be formally ratified by the organisation. ${ }^{11}$ Notwithstanding, Victoria Police is taking a proactive stance in terms of revising the Part-time Employment Policy and in addressing cultural issues that impact on quality part-time work in the organisation. The challenge for Victoria Police, and indeed for the Policing and Quality Part-time Work Project, will be to move beyond an understanding that organisational cultural discourses and practices that underpin the restricted quantity and quality of part-time work can be simply dealt with by educating managers and full-time co-workers. In exploring the resistance of managers to part-time work in a UK police force, Dick (2004) found this resistance to be rooted in the institutional and historical context of policing, which influenced the attitudes of managers who attempted to negotiate between the conflicting demands of employees' desire to work part-time and organisational responses to operational demands. Unless there is recognition of organisational and institutional barriers to part-time work, attempts to change individuals' attitudes are likely to achieve only limited effects. Cultural change that would support the effective integration of part-time and full-time work therefore requires not only 'education' of people, particularly managers, but also requires addressing the structural and institutional constraints and processes that reflect and reinforce perceptions of part-time policing employees as 'part-time and partcommitted'.

\section{References}

Australian Bureau of Statistics [ABS] (2005) Labour Force Australia, February 2005, Cat. No. 6202.0. Canberra: ABS.

Australian Industrial Relations Commission [AIRC] (2004) Victorian Public Service Agreement. AG834607 PR947441 2 June 2004, Melbourne.

Australian Institute of Criminology [AIC] (2003) The Composition of Australia's Police Services as at June 30 2003. <http://www.aic.gov.au/policing/stats/2003>.

Bailyn L, Fletcher J (2003) The Equity Imperative: Reaching Effectiveness Through the Dual Agenda, Center for Gender in Organizations (CGO) Insights Briefing Note Number 18, July.

British Association of Women Police [BAWP] (2002) Gender Agenda: Women Officers Clearing Hurdles Together.

$<$ TTUUhttp://www.bawp.org/New/Documents/gender.pdf $>$.

Chalmers J, Campbell I, Charlesworth S (2005) Part-time Work and Caring Responsibilities in Australia: Towards an Assessment of Job Quality. Labour \& Industry 15(3), 41-66.

Chan J (1996) Changing Police Culture British Journal of Criminology 36(1), 109-134.

Charlesworth S (1999) Working Mums: the Construction of Women Workers in the Banking Industry. Journal of Interdisciplinary Gender Studies 4 (2) 12-28.

Charlesworth S, Campbell I, Probert B with Allan J, Morgan L (2002) Balancing Work and Family Responsibilities: Policy Implementation Options A Report for the Victorian Department of Premier and Cabinet \& Department of Innovation, Industry and Regional Development. Melbourne: Centre for Applied Social Research, RMIT University.

de Kretser L. Police Jobs for the Girls. Herald Sun 29 April 2003. 
de Kretser L, Butler M. Men Just Won’t Cop It: Police Quotas Queried. Herald Sun, 30 April 2003.

Dick P (2004) Between a rock and a hard place: the dilemmas of managing part-time working in the police service. Personnel Review 33(3), 302-321.

Dick P, Cassell C (2004) The Position of Police Women: A Discourse Analytic Study. Work, Employment and Society, 18(1), 51-72.

Edwards C, Robinson O (1999) 'Managing Part-timers in the Police Services: a Study of Inflexibility’ Human Resource Management Journal 9(4), 5-18.

Epstein R 'More women needed in Victorian Police force' Australian Broadcasting Commission[ABC] News 29 April 2003.

Eveline J, Harwood S (2002) Changing the Culture from Within: Changing the Gendered Organisation of Police Work. Perth: Centre for Women and Business University of Western Australia.

Eveline J, Harwood S (2003) Report to the Commissioner of Police Redressing the Gendered Workplace Culture of Policing: A collaborative project between the Western Australia Police Service and the University of Western Australia, Unpublished.

Fagan C (1999) Developing the concept of lifetime working hours: the potential role of part-time work. In: Boulin J.-Y., J Hoffmann J, eds, New Paths in Working Time Policy, pp. 51-74. Brussels: European Trade Union Institute.

Fleming J, Lafferty G (2003) Equity confounded? Women in Australian Police Organisations. Labour \& Industry 13(3) 37-49.

Green F (2005) Demanding Work: Job Quality in the Affluent Economy. Cornell: Cornell University Press.

Hogan M (1999) Equal Opportunity in Part-time Policing. Proceedings of the Second Australasian Conference on Women and Policing, 7-9 July 1999, Canberra.

Jenkins C (2000) Gender Just? Police Review www.janes.com 3 November 2000.

Junor A (1998) Permanent Part-Time Work: New Family-Friendly Standard or High Intensity Cheap Skills?, Labour \& Industry 8 (3) 77-95.

Leane S, Durand J (2002) Women and Discrimination - A Policing Perspective Paper Proceedings of the Third Australasian Women and Policing Conference, 20-23 October 2002, Canberra.

Manders T (2000) Women in Policing - the view from Europe Journal for Women and Policing 7(2), 19-23.

Poaline EA (2003) Taking stock: Towards a richer understanding of police culture Journal of Criminal Justice 32, 199-214.

Prenzler T, Hayes H (2000) 'Measuring Progress in Gender Equity in Australian Policing' Current Issues in Criminal Justice 12(1) 21-38.

Prenzler T (1997) Is there a Police Culture? Australian Journal of Public Administration 56(4), 47-56.

Robertson D (2002) Surviving the Implementation of a Policy Change to Working Conditions within the Victoria Police Force. Proceedings of the Third Australasian Women and Policing Conference, 20-23 October 2002, Canberra.

Rose P (2002) New Zealand Police- Flexible Employment and Best Practice. Proceedings of the Third Australasian Women and Policing Conference, 20-23 October 2002, Canberra.

Short K (2004) Victoria Police Career Barriers Project: Final report, April 2004, Unpublished.

Victoria Police (2002) The Way Ahead: Strategic Plan 2003-2008, Victoria Police, Melbourne. 
Victoria Police (2004a) Partners at Work Part-time Employment Review, Final Report, May 2004, (Draft Report) Unpublished.

Victoria Police (2004b) Annual Report 2003/2004. Melbourne: Victoria Police. Williams J (2000) Unbending Gender Why Family and Work Conflict and What to do About It Oxford University Press, New York.

Whittenbury K (2003) Exploring the Taken-for-granted: Cultural and Structural Influences on Men's and Women's Perceptions of Family Life in a Rural Community. PhD thesis. Charles Sturt University, Wagga Wagga, NSW.

\section{Acknowledgements}

We are grateful to Jenny Chalmers who made comments on an earlier version of this paper. Any errors are our own.

\section{Endnotes}

${ }^{1}$ However it should be noted that unlike the Australian workforce where part-time employment has been available for a considerable time, part-time employment in most Australian policing jurisdictions has been available for less than a decade.

${ }^{2}$ National comparative data on the composition of Australia's Police Services indicate that in June 2003 the proportion of women employed as sworn police officers in Victoria Police (17.8 percent) was below that in the Northern Territory Police (25.3 percent), the Australian Federal Police (24.4 percent), NSW Police (23.8 percent), South Australia Police (22.0 percent), Queensland Police (21.1 percent), Tasmania Police (21.1 percent) but above Western Australia Police(15.1 percent) (AIC 2003).

${ }^{3}$ While only 4.4 percent of the Victoria Police workforce is part-time, 16.2 percent of Victorian Public Service employees are employed part-time.

${ }^{4}$ The Partners at Work Scheme is run through Industrial Relations Victoria, Department of Innovation, Industry and Regional Development.

${ }^{5}$ This research project is supported by the Australia Research Council and Victoria Police. (Linkage Grant LP 0453912).

${ }^{6}$ The second stage of the project involves action research in two pilot study sites. In each site the main aims are to identify any operational and cultural impediments to, as well as innovative ways of, supporting, quality part-time work. The third and final stage of the project is concerned with the evaluation of organisational interventions designed to improve the quality of part-time work both in the pilot areas and more generally across Victoria Police.

${ }^{7}$ Probationary constables are confirmed once they have completed a Diploma of Public Safety. While the Diploma is competency based, regulations limit the time for completion of the Diploma to a maximum of three years.

${ }^{8}$ This can result in cost reductions, which may be viewed favourably by some managers.

${ }^{9}$ Often the two experiences are punctuated by a period of maternity leave.

${ }^{10}$ We note that even full-time work could be constructed as 'part-time' in a twenty-four hour, seven day a week operational environment.

${ }^{11}$ As at June 2005. 
Table 1: Police (Sworn) Employees by Classification and Sex, 30 June 2004

\begin{tabular}{|c|c|c|c|c|c|c|c|c|c|c|c|c|}
\hline Rank & & Full & ime & & & Part & ime & & Tota & Swor & Emplo & ees \\
\hline & $\mathbf{M}$ & $\mathbf{F}$ & Total & $\% \mathbf{F}$ & $\mathbf{M}$ & $\mathbf{F}$ & Total & $\% \mathbf{F}$ & $\mathbf{M}$ & $\mathbf{F}$ & Total & $\% \mathbf{F}$ \\
\hline Chief Commissioner & & 1 & 1 & 100.0 & & & & & & 1 & 1 & 100.0 \\
\hline Deputy Commissioner & 2 & & 2 & 0.0 & & & & & 2 & & 2 & 0.0 \\
\hline Assistant Commissioner & 8 & & 8 & 0.0 & & & & & 8 & & 8 & 0.0 \\
\hline Commander & 13 & 1 & 14 & 7.1 & & & & & 13 & 1 & 14 & 7.1 \\
\hline Chief Superintendent & 2 & & 2 & 0.0 & & & & & 2 & & 2 & 0.0 \\
\hline Superintendent & 63 & 1 & 64 & 1.6 & & & & & 63 & 1 & 64 & 1.6 \\
\hline Chief Inspector & 22 & & 22 & 0.0 & & & & & 22 & & 22 & 0.0 \\
\hline Inspector & 244 & 11 & 255 & 4.3 & & & & & 244 & 11 & 255 & 4.3 \\
\hline Senior Sergeant & 549 & 32 & 581 & 5.5 & & & & & 549 & 32 & 581 & 5.5 \\
\hline Sergeant & 1605 & 120 & 1725 & 7.0 & 8 & 11 & 19 & 57.9 & 1613 & 131 & 1744 & 7.5 \\
\hline Senior Constable & 4601 & 730 & 5331 & 13.7 & 56 & 327 & 383 & 85.4 & 4657 & 1057 & 5714 & 18.5 \\
\hline Constable & 1420 & 665 & 2085 & 31.9 & 6 & 12 & 18 & 66.7 & 1426 & 677 & 2103 & 32.2 \\
\hline Total Police & 8529 & 1561 & 10090 & 15.5 & 70 & 350 & 420 & 83.3 & 8599 & 1911 & 10510 & 18.2 \\
\hline Recruits in Training & 112 & 80 & 192 & 41.7 & & & & & 112 & 80 & 192 & 41.7 \\
\hline Police and Recruits & 8641 & 1641 & 10282 & 16.0 & 70 & 350 & 420 & 83.3 & 8711 & 1991 & 10702 & 18.6 \\
\hline
\end{tabular}

Adapted from Victoria Police (2004b) Annual Report 2003/2004. 